\title{
The Natural History of Idiopathic Frozen Shoulder
}

\author{
A 2- to 27-year Followup Study
}

\author{
Heidi Vastamäki MD, Jyrki Kettunen PT, PhD, \\ Martti Vastamäki MD, PhD
}

Received: 21 May 2011/Accepted: 28 October 2011/Published online: 17 November 2011

(C) The Association of Bone and Joint Surgeons (B) 2011

\begin{abstract}
Background The natural history of spontaneous idiopathic frozen shoulder is controversial. Many studies claim that complete resolution is not inevitable. Based on the 40-year clinical experience of the senior author, we believed most patients with idiopathic frozen shoulder might have a higher rate of resolution than earlier thought. Questions/purposes We determined the length of symptoms, whether spontaneous frozen shoulder recovered without any treatment, and whether restored ROM, pain relief, and function persisted over the long term.

Methods We retrospectively reviewed 83 patients treated for frozen shoulder ( 84 shoulders; 56 women) 2 to 27 years (mean, 9 years) after initial consultation. The mean age at
\end{abstract}

One of the authors (HV) has received funding from the Finnish Society for Surgery of the Hand.

All ICMJE Conflict of Interest Forms for authors and Clinical Orthopaedics and Related Research editors and board members are on file with the publication and can be viewed on request.

Each author certifies that his or her institution approved the human protocol for his investigation, that all investigations were concluded in conformity with ethical principles of research, and that informed consent for participation in the study was obtained.

This work was performed at ORTON Orthopaedic Hospital.

H. Vastamäki (\)

ORTON Research Institute, Invalid Foundation,

Tenholantie 10, FIN-00280 Helsinki, Finland

e-mail: heidi.vastamaki@fimnet.fi

J. Kettunen

Arcada University of Applied Sciences, Helsinki, Finland

M. Vastamäki

Department of Hand and Shoulder Surgery, ORTON

Orthopaedic Hospital, Helsinki, Finland

e-mail: martti.vastamaki@orton.fi onset of symptoms was 53 years. Fifty-one of the 83 patients (52 shoulders) were treated with observation or benign neglect only (untreated group), and 32 had received some kind of nonoperative treatment before the first consultation with the senior author (nonoperative group). We also evaluated all 20 patients (22 shoulders; 13 women) with spontaneous frozen shoulder who underwent manipulation under anesthesia during the same time (manipulation group). The mean age of these patients was 49 years. The minimum followup was 2 years (mean, 14 years; range, 2-24 years). We determined duration of the disease, pain levels, ROM, and Constant-Murley scores.

Results The duration of the disease averaged 15 months (range, 4-36 months) in the untreated group, and 20 months (range, 6-60 months) in the nonoperative group. At last followup the ROM had improved to the contralateral level in $94 \%$ in the untreated group, in $91 \%$ in the nonoperative group, and in $91 \%$ in the manipulation group. Fifty-one percent of patients in the untreated group, $44 \%$ in the nonoperative group, and $30 \%$ in the manipulation group were totally pain free at rest, during the night, and with exertion. Pain at rest was less than 3 on the VAS in $94 \%$ of patients in the untreated group, $91 \%$ in the nonoperative group, and $90 \%$ of the manipulation group. The Constant-Murley scores averaged $83(86 \%)$ in the untreated group, $81(77 \%)$ in the nonoperative group, and $82(71 \%)$ in the manipulation group, reaching the normal age- and gender-related Constant-Murley score.

Conclusions We found $94 \%$ of patients with spontaneous frozen shoulder recovered to normal levels of function and motion without treatment.

Level of Evidence Level IV, therapeutic study. See Guidelines for Authors for a complete description of levels of evidence. 


\section{Introduction}

Although documented frequently during the last 30 years $[1,2,5-8,10,12-15,18,19]$, the outcome of idiopathic frozen shoulder after nonoperative treatment is controversial. However, the natural course of a frozen shoulder is obscure owing to scanty literature $[2,5,17]$. Codman stated 77 years ago, "even the most protracted cases recover with or without treatment in about two years" [3]. The natural history has been reported only in two articles [5, 17]. In a prospective study of 41 patients, only $39 \%$ regained complete shoulder movements in 5 to 10 years [17], but in a similar study of 45 patients, $89 \%$ achieved ConstantMurley scores of 80 or greater [5]. Eighty-nine percent to $100 \%$ of patients reportedly have complete or nearly complete relief of pain and restoration of motion after nonoperative treatment $[5,6,12,14,15]$. However, numerous authors have reported complete resolution is not inevitable [7, 8, 17-19]. Some of these studies lacked objective or subjective outcome criteria [17, 19], strict inclusion criteria [19], or physical followups [8]. In a well-conducted study of 62 patients, $50 \%$ still had either mild pain or stiffness of the shoulder after 7 years [18]. Therefore, it is unclear whether pain is relieved and motion and function restored with nonoperative treatment. Based on the 40-year clinical experience of the senior author (MV), we believe the outcome of spontaneous frozen shoulder without any treatment modalities might be better than stated.

We therefore determined (1) the length of the symptoms, and whether (2) ROM was restored, (3) pain was relieved, and (4) function was restored and maintained in patients with spontaneous, idiopathic frozen shoulder without treatment.

\section{Patients and Methods}

We retrospectively evaluated approximately 15,000 outpatient records and identified 231 patients with spontaneous idiopathic frozen shoulder seen by the senior author between 1975 and 1998. Additionally, from 1999 to 2006, the senior author collected the names of patients with idiopathic frozen shoulder seen at his offices and at his hospital. The criteria for inclusion were: (1) no trauma or only very minor shoulder trauma, (2) marked loss of active and passive shoulder motion (forward flexion $\leq 135^{\circ}$, abduction $\leq 125^{\circ}$, severe restriction in external rotation), (3) pain with extreme ROM, (4) normal findings in the true AP radiograph of the glenohumeral joint, (5) no particular treatment for frozen shoulder (no manipulation under anesthesia, no surgical treatment, no intraarticular corticosteroid injection), and (6) no suspicion of rotator cuff tear at the first consultation. We included patients with diabetes mellitus and thyroid dysfunction. We excluded patients with: (1) intrinsic glenohumeral disorders such as glenohumeral arthritis or rotator cuff tear, (2) history of substantial shoulder trauma, (3) previous or subsequent shoulder surgery or surgery on the same upper extremity, (4) reflex sympathetic dystrophy of the ipsilateral hand, (5) previous or subsequent fracture of the same upper extremity, or (6) insufficient patient status records (no ROM mentioned). We obtained permission to perform this study from the ethics committee of the study's hospital district.

Of the 231 patients with spontaneous frozen shoulder, 34 had died, 10 were not reachable (no address available), and one lived abroad. This left 186 patients (81\%), and 155 $(67 \%)$ agreed to participate. The two main reasons for nonparticipation (31 patients) were poor physical condition and a lengthy trip for followup. At the followup, we excluded another 52 patients for not fulfilling the inclusion criteria for various unexpected reasons (previous shoulder trauma not recorded at the first consultation, previous or subsequent shoulder or ipsilateral upper extremity surgery, surgical treatment of the frozen shoulder after the first consultation, or intraarticular corticosteroid injection). We excluded patients with secondary frozen shoulders, and patients with carpal tunnel or cubital tunnel surgery performed for the same upper extremity. This left 103 patients (44\%) with idiopathic frozen shoulder (106 shoulders) treated only by observation or nonoperative treatment at the initial consultation. Of these, 20 patients ( 22 shoulders) underwent manipulation under anesthesia elsewhere. They served as the manipulation group. Of the remaining 83 patients ( 84 shoulders), 32 had received nonoperative treatment such as physiotherapy, and they served as the nonoperative group. Fifty-one patients (52 shoulders) received no treatment other than observation, and they served as the untreated group (Table 1). Eighteen patients had bilateral frozen shoulders, but we included both shoulders of only three because in 15 patients the nonincluded shoulder was frozen either before or after the first consultation. Two patients $(2.5 \%)$ had simultaneous bilateral frozen shoulders. The minimum followup was 2 years. The dominant shoulder was involved in $36 \%$ and the right shoulder in $37 \%$. Twenty-three of the 103 patients (22\%) related the onset of the symptoms to some kind of provocative action, such as throwing a rope. For the 22 patients for whom data were available in the medical records, shoulder stiffness had lasted 2.5 months (range, 0.5-7 months) before the first consultation. Patients in the nonoperative group already had treatment modalities such as acupuncture (two patients, six and eight sessions), ultrasound (two patients), physiotherapy (15 patients, eight to 20 sessions, seven reported worsening symptoms), and subacromial corticoid injections (20 patients, one to five 


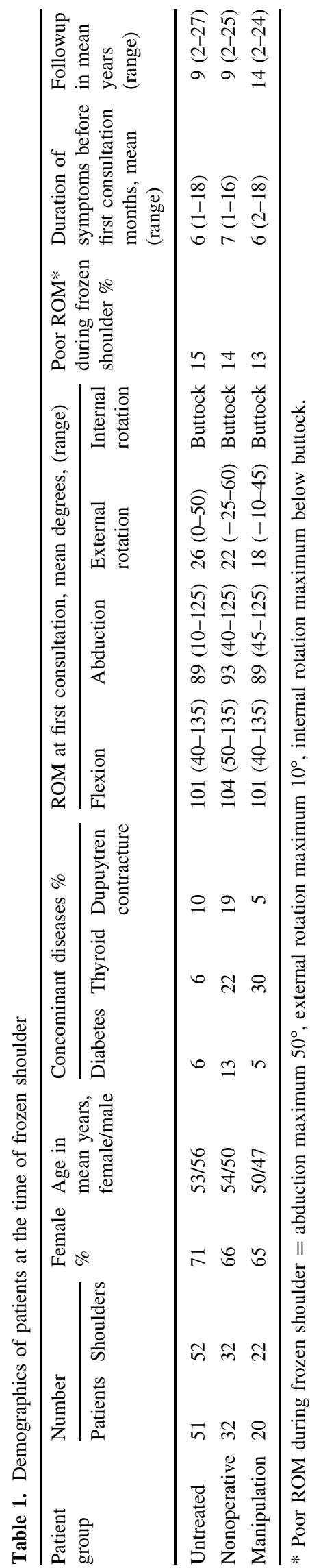

injections, mean, two injections). We excluded the five patients who received intraarticular corticosteroids. Five patients had more than one nonoperative treatment. Twenty patients without labral or cuff tears underwent ultrasound examination of the shoulder, arthrography, or MRI. At the last evaluation, the mean age of the patients was 62 years (range, 46-78 years) in the untreated group and in the nonoperative group (range, 45-77 years), and 63 (range, $36-81$ years) in the manipulation group.

After the initial appointment, 103 patients in the untreated and nonoperatively treated groups were subjected to observation. Although manipulation under anesthesia was the practice of the senior author during the whole period, he did not consider these 103 patients in need of that treatment. The indications for manipulation were (1) severe pain 5 to 6 months after the onset of symptoms, (2) severe restriction of motion restraining work activities 6 to 9 months after the onset of symptoms, and (3) a specific request from the patient 1 to 3 months earlier than indications (1) or (2). Approximately 30 other patients underwent manipulation by the senior author during that period.

We observed no difference between the mean ages of the men and women (Table 1). All patients were at approximately the same stage of disease at the first consultation (Stages 2-3/3, using the staging system of Dudkiewicz et al. [6]), and all had pain. At followup the mean ConstantMurley score was evaluated in three different ways: means, by subgrouping to normalized Constant-Murley, and by age- and gender-related Constant-Murley scores.

Initial evaluation included a detailed medical history, physical examination, and, in certain cases, AP radiographs. Most patients already had shoulder radiographs before the first consultation. No subjective or objective assessment occurred at this initial evaluation.

Questionnaires (Appendix 1) were sent to the patients along with an invitation to the study and included questions concerning demographics, and symptoms of the oncefrozen shoulder, including pain evaluation on a VAS (range, $0-10 ; 0=$ no pain to $10=$ maximal imaginable pain). Additionally, patients received the Simple Shoulder Test questionnaire [20]. The patients completed these questionnaires at home and returned them at followup.

All 103 patients in the untreated group and nonoperatively treated group and 52 subsequently excluded patients (a total of 155 patients with verified idiopathic spontaneous frozen shoulder) underwent a physical examination by one independent observer (HV) at followup. That observer recorded medical histories again for the patients and checked treatment records from other hospitals. Active and passive shoulder ROM measurements were similar to those from the first consultation obtained with a handheld goniometer, assessing bilateral active motion simultaneously 
with the patient in the standing position. Evaluation of forward flexion and abduction was by measurement of the angle formed by the arm and thorax. External rotation was measured with the arm adducted and the elbow at the side and flexed to $90^{\circ}$. Internal rotation of the arm behind the back assessment was determined by the vertebral level that could be reached by the dorsum of the hand. The observer assessed shoulder function with the Constant-Murley score [4] with absolute and age- and gender-related scores calculated [11]. Shoulder strength was evaluated by manual muscle testing, and strength in abduction for the Constant-Murley score was evaluated using a Salter spring balance up to $11 \mathrm{~kg}$ at increments of $0.2 \mathrm{~kg}$. Patients indicated the presence of a painful arc sign by yes or no. We also took a true AP radiograph of the index shoulder in external rotation.

We used the Student's t-test to determine differences in the length of the symptoms between the untreated group and the nonoperative group. ANOVA was used to determine differences in ROM, pain relief, and function in the untreated group compared with treated groups. Differences in categorical variables were tested with Pearson's chisquare test or with Fisher's exact test. We performed all statistical analyses with SPSS (Version 18.0; SPSS Inc, Chicago, IL, USA).

\section{Results}

The duration of the disease was similar $(\mathrm{p}=0.080)$ in the untreated group and in the nonoperative group: means of 15 months (range, 4-36 months) and 20 months (range, 6-60 months), respectively. The disease lasted more than 24 months in $14 \%$ of patients in the untreated group and in $29 \%$ in the nonoperative group. In the untreated group, the recovery time for the eight patients with the worst ROM at the initial evaluation was similar $(\mathrm{p}=0.101)$ to that for the other two groups (19 versus 14 months).

Active and passive ROM of the index shoulders improved to normal in $94 \%$ in the untreated group, $92 \%$ in the nonoperative group, and $89 \%$ in the manipulation group. When comparing ROM of the index shoulder with that of the contralateral shoulder at followup, there were no differences in the mean ROM within or between the groups studied (all $\mathrm{p}$ values greater than 0.343) (Table 2). Women had worse $(\mathrm{p}=0.018)$ external rotation at the time of initial presentation than men (mean difference, $8.6^{\circ}$ ), and patients having the worst internal rotation were more often ( $p=0.032)$ women (18 women versus three men), but we observed no differences in ROM at followup. The eight patients with the worst ROM in the untreated group recovered just as well $(\mathrm{p}=0.001)$ as the others regarding followup ROM, except that their external rotation was inferior $(\mathrm{p}=0.040)$ : $45.0^{\circ}$ versus $52.7^{\circ}$, respectively. In seven patients with diabetes, followup flexion was $15.7^{\circ}$ worse $(p=0.003)$ and followup abduction was $17.2^{\circ}$ worse $(p=0.003)$ compared with flexion and abduction of the other patients. Patients with hypothyroidism also had a tendency $(p=0.058)$ toward worse ROM than the others.

We observed no differences in pain at rest, with exertion, at night, or overall pain level in Constant-Murley scores between the untreated and treated groups or for patients with the worst ROM (Table 2). Of the patients with frozen shoulders for 24 months or more (six in the untreated group, eight in the nonoperative group), four in the untreated group and five in the nonoperative group were totally pain free. At followup we saw no differences in subgroups by normalized Constant-Murley scores, or by age- or gender-related Constant-Murley scores (Table 3). Patients with Constant-Murley scores less than 80 showed a tendency $(\mathrm{p}=0.058)$ toward longer duration of the frozen shoulder ( 22 versus 16 months). Those patients were as old as the other patients and had excellent mean Simple Shoulder Test results (10 versus 11/12). Even the patients with poor ROM still reached the age- and gender-related Constant-Murley scores in both groups. Patients with the longest duration of frozen shoulder (24 months or more) did not differ from the others regarding mean ConstantMurley score (82.0 versus $83.8 ; \mathrm{p}=0.548$ ) or the Simple Shoulder Test (11 versus $11 ; \mathrm{p}=0.908$ ).

Table 2. Mean active ROM of shoulder and shoulder pain at followup

\begin{tabular}{|c|c|c|c|c|c|c|c|c|c|}
\hline \multirow{2}{*}{$\begin{array}{l}\text { Patient } \\
\text { group }\end{array}$} & Flexion mean & Abduction mean & External rotation & Internal & \multicolumn{3}{|c|}{ VAS pain*** mean (range) } & \multirow{2}{*}{$\begin{array}{l}\text { No pain on } \\
\text { Constant- } \\
\text { Murley } \\
\text { score \% }\end{array}$} & \multirow{2}{*}{$\begin{array}{l}\text { VAS } * * *<3 \\
\text { at rest } \%\end{array}$} \\
\hline & \multicolumn{4}{|c|}{ Frozen shoulder/contralateral shoulder* } & Rest & Activity & Night & & \\
\hline Untreated & $157 / 157$ & $175 / 168$ & $52 / 52$ & $\mathrm{~L} 1 / \mathrm{T} 12$ & $0.8(0-3)$ & $1.1(0-8)$ & $0.6(0-7)$ & 63 & 94 \\
\hline Nonoperative & $155 / 153$ & $169 / 166$ & $50 / 49$ & $\mathrm{~L} 1 / \mathrm{L} 1$ & $0.5(0-7)$ & $1.4(0-8)$ & $1.0(0-8)$ & 72 & 91 \\
\hline Manipulation & $159 / 160$ & $174 / 174$ & $50 / 51$ & L1/T12 & $0.8(0-6)$ & $1.8(0-8)$ & $0.9(0-7)$ & 65 & 90 \\
\hline
\end{tabular}

* Once frozen shoulder; ** Level reached by the dorsum of the hand; *** VAS-scale $0=$ no pain to $10=$ maximum imaginable pain. 


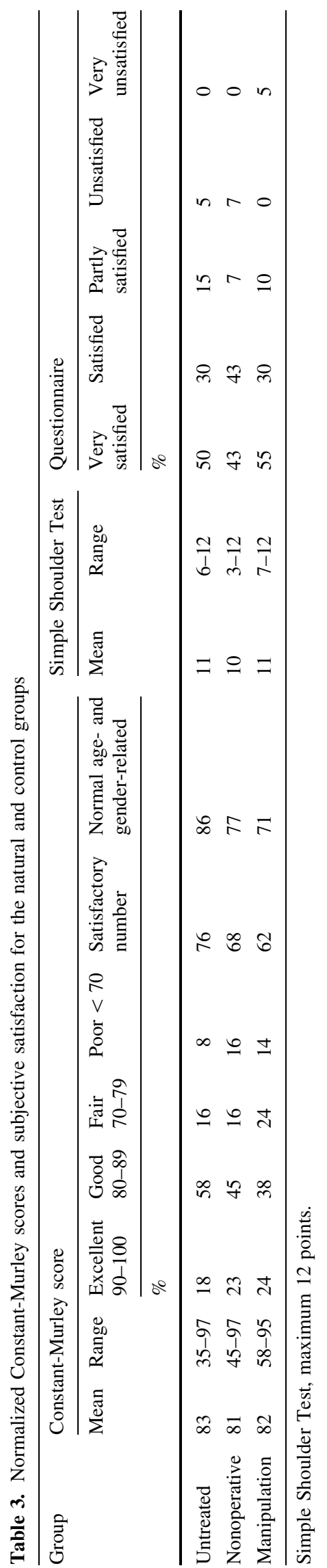

According to a questionnaire completed by our patients, four were dissatisfied with their end result (Appendix 1, Question 29). One of these four patients was undergoing cancer treatment, one patient with diabetes had moderate arthrosis in the glenohumeral joint, and one woman was subjectively dissatisfied although her Constant-Murley score (78) suggested good function. One woman had diabetes for 62 years and also had hypothyroidism and Dupuytren's contracture in both hands. Her ConstantMurley score was only 45 . The seven patients with diabetes reached an age- and gender-related Constant-Murley score less often than others did $(\mathrm{p}=0.013)$. No patient had ceased working because of any ipsilateral shoulder problem, however, $46(56.1 \%)$ retired owing to age, and 10 $(55.6 \%)$ were not working owing to a nonrelated illness. Patients who fulfilled all three criteria for poor ROM recovered more slowly $(\mathrm{p}=0.043)$ (28.8 months) compared with patients who fulfilled two of the criteria (16 months), or one criterion (12 months). However, the patients' Constant-Murley scores at last followup did not differ. The three patients in the untreated group with diabetes had ranges of motion inferior to those without diabetes (flexion, $26^{\circ}$; abduction, $24^{\circ}$; external rotation, $2^{\circ}$ ), and their followup ranges of motion were similarly inferior $\left(7^{\circ}\right.$; superior $\left.3^{\circ} ; 4^{\circ}\right)$.

\section{Discussion}

The natural course of idiopathic frozen shoulder is obscure owing to few published studies $[2,5,17]$. Therefore, it is unclear whether pain is relieved and motion and function restored without treatment. Based on the 40-year clinical experience of the senior author, we believe the outcome of spontaneous frozen shoulder without any treatment modalities might be better than stated. We wished to know the long-term natural outcome of spontaneous, idiopathic frozen shoulders. We therefore determined (1) the length of the symptoms and whether (2) ROM was restored, (3) pain was relieved, and (4) function was restored and maintained in patients without treatment for spontaneous, idiopathic frozen shoulder.

We acknowledge limitations to our study. First, we used the Constant-Murley score, a popular score for assessing shoulder function. However, the reliability of the Constant-Murley score has been questioned [9], and for frozen shoulder may not be the best choice when muscle strength is included, because most patients with frozen shoulder cannot abduct their shoulders enough to lift 25 pounds reliably [16]. We used no other objective functional scores, but adopted the age- and gender-related Constant-Murley scores. The strength of the normal 


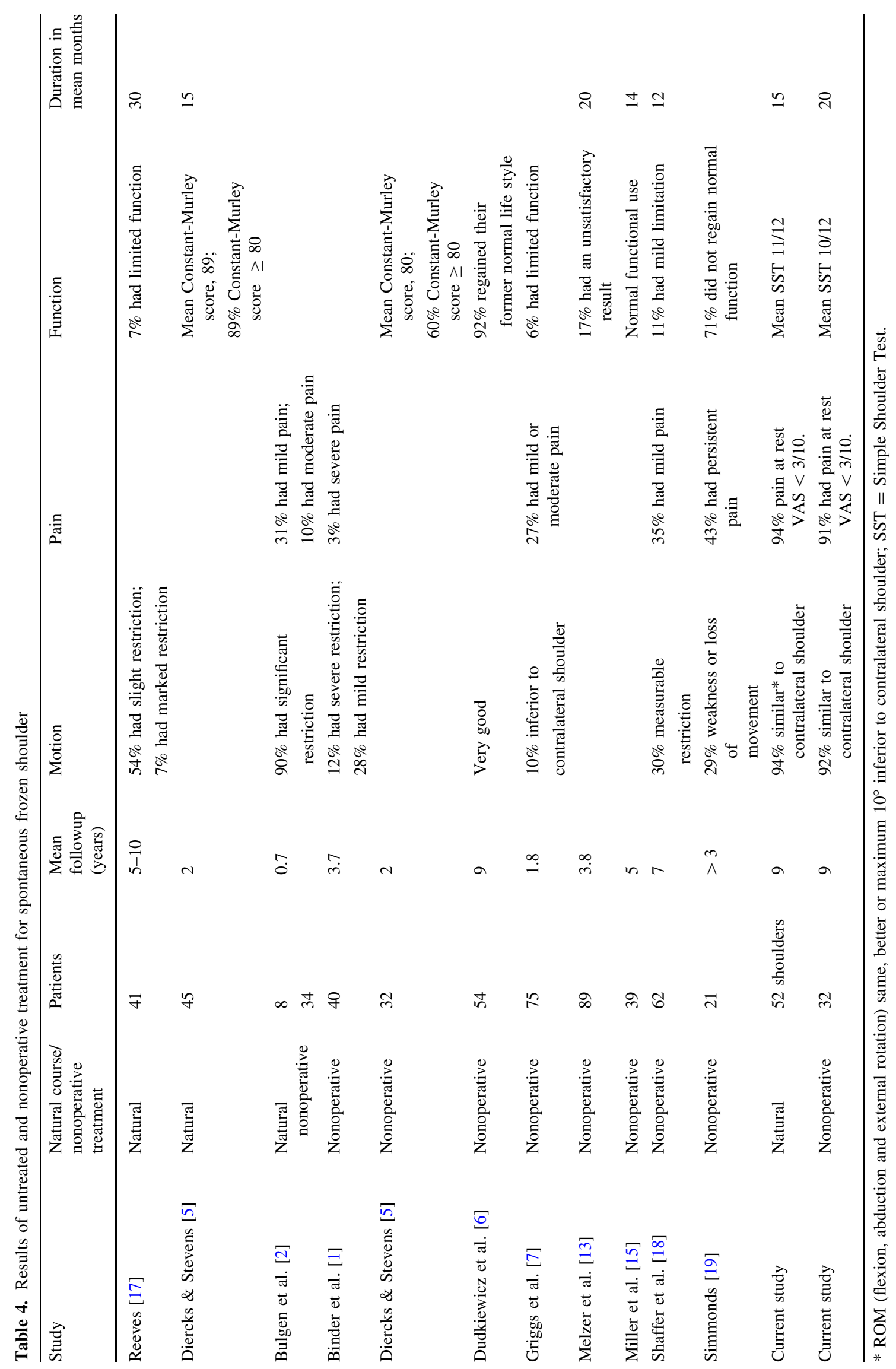


shoulder may differ by gender and deteriorates with age. Thus, the Constant-Murley score also may decrease in absolute value while still reflecting a normal score. We found men had higher Constant-Murley scores, apparently owing to originally greater strength. Second, we did not obtain Constant-Murley scores or administer the Simple Shoulder Test at the time the patients initially were seen. Although longitudinal assessment of outcome measures would provide additional insight into the progress, we had only ROM and strength measurements. We excluded patients whose ROM was inadequately documented in their medical records, and included only patients with appropriate records. For some patients, rotator cuff tendinitis preceded the frozen shoulder. For these patients, we calculated that the onset was 2 months before the patient experienced true limitation of ROM. In some cases, exact length of recovery was difficult for patients to remember.

The shortest mean reported duration of spontaneous frozen shoulder without any treatment is 15 months [5], and the longest 30 months [17]. In the former study, the mean followup was only 2 years, and some patients might not have totally recovered during this period. We found a mean resolution of 15 months. The shortest mean duration of recovery time after nonoperative treatment is 12 months in a well-documented 7-year followup study [18], and the longest was 20 months, as with our patients [13] (Table 4). The number of patients treated nonoperatively in our study was small, and therefore, this might influence the results.

Reeves [17] reported that $54 \%$ of untreated patients had slight restriction and $7 \%$ had marked restriction at 5 to 10 years. In contrast, $94 \%$ of our untreated patients achieved ROM similar to that of the contralateral shoulder. We cannot explain this difference. Although we included patients with diabetes and with thyroid disease in our study, their ROM recovered well. After nonoperative treatment, Binder et al. [1] reported $12 \%$ of patients had severe restriction and $28 \%$ had mild restriction at 4 years, and Shaffer et al. [18] reported $30 \%$ had measurable restriction at 7 years. However, even better results after nonoperative treatment have been reported [6] (Table 4). After nonoperative treatment, $92 \%$ of our patients achieved ROM similar to that of the contralateral shoulder. We therefore believe ROM recovery after nonoperative treatment for an idiopathic frozen shoulder is better than reported in some studies.

We found no published studies regarding pain in an untreated frozen shoulder. Diercks and Stevens [5] stated
$89 \%$ of their patients had normal or near-normal painless shoulder function, but they used only the ConstantMurley questionnaire and not a VAS. In our study, pain at rest was less than $3 / 10$ on a VAS in $94 \%$ of patients showing good recovery. After nonoperative treatment, $43 \%$ of patients were reported to have persistent pain at 3 years [19], 35\% had mild pain at 7 years [18], and $27 \%$ had mild or moderate pain at 1.8 years [7]. For our patients, pain at rest was less than $3 / 10$ in $91 \%$ (Table 4).

Seven percent of untreated patients had limited function at 5 to 10 years according to Reeves [17], and Diercks and Stevens [5] reported a mean Constant-Murley score of 89 for their patients, with $89 \%$ achieving a score of 80 or greater. We found a mean Constant-Murley score in the untreated group was 83, the normal age- and gender-related score was 86, and the Simple Shoulder Test was 11/12, showing patients achieved good functional recovery. After nonoperative treatment, Diercks and Stevens [5] reported a mean Constant-Murley score of 80, with $60 \%$ of patients achieving a score of 80 or greater. Our patients achieved a mean Constant-Murley score of 81. However, Simmonds [19] reported that $71 \%$ of patients did not regain normal function by 3 years, and Melzer et al. [13] reported $17 \%$ of their patients had an unsatisfactory result at 4 years. Better function after nonoperative treatment has been reported in several studies [6, 7, 15] (Table 4).

We determined the natural history of idiopathic frozen shoulder, the length of symptoms, recovery of ROM, pain relief, and function at a mean of 9 years. Our results were similar to those reported by Diercks and Stevens [5], but better than those reported by Reeves [17], whose patients took twice as long as ours for recovery from their frozen shoulder. We cannot explain this difference. Diercks and Stevens [5] stated supervised neglect yields better outcomes than intensive physical therapy and passive stretching in patients with frozen shoulder. Patients in our untreated group had better pain relief, ROM, and function than patients in our nonoperative group. Our study and the literature shows most patients with idiopathic frozen experience resolution without any treatment. We believe it is important to be able to tell a patient with some confidence that an idiopathic frozen shoulder generally recovers well without any restriction of motion or pain.

Acknowledgments We thank Carol Norris $\mathrm{PhD}$, for language revision. 


\section{Appendix 1}

Questionnaire, frozen shoulder

Name tag

Date

The questions below regard your right/left shoulder that was treated for frozen shoulder.

Circle the appropriate choice. At the end of the questionnaire is room for free comments. Unclear questions can be discussed at the examination.

\section{Background}
(1) Gender:
Female
[0]
Male
[1]
(2) Dominant hand:
Left
[0]
Right
[1]
(3) Marital status:
Unmarried [1]
Partnership [3]
Married
Widow(er) [5]
Divorced

(4) How do you live?
Alone
With spouse or partner
With friend or relative
In an institution

[1]

(5) Are you employed at the moment? Yes [1] No [0]

(6) What is/was your profession?

(7) Are you retired at the moment? Yes [1] No [0]

If you answered No, please continue to question $\mathbf{1 0 .}$

(8) Did you retire because of the frozen shoulder? Yes [1] No [0]

If you answered Yes, please specify year

(9) After you retired, has your shoulder distress:

\section{Been relieved \\ Stayed unchanged \\ Deteriorated}

(10) Do you smoke?

No

[0]

Quit

Not more than one pack per day

More than one pack per day

(11) How much alcohol do you use? One restaurant portion: one bottle of beer or a glass of wine $(12 \mathrm{cl})$ or one portion of liquor $(4 \mathrm{cl})$

$\begin{array}{ll}\text { I don't use alcohol } & {[0]} \\ 1-5 \text { restaurant portions per year } & {[1]} \\ 0-5 \text { restaurant portions per month } & {[2]} \\ 1-5 \text { restaurant portions per week } & {[3]} \\ \text { 6-10 restaurant portions per week } & {[4]} \\ \text { More than 10 restaurant-portions per week } & {[5]}\end{array}$




\section{(12) Health Condition}

In the following you see a list of general diseases. Please mark a tick (x) in the first column if you suffer from the disease, if not, then you can continue to the next line. If you have the disease, please fill out whether you are receiving treatment for it (ie, drugs or other treatment). Fill out the third column regarding how disease limits your life.

\begin{tabular}{|l|l|l|l|l|l|l|}
\hline & \multicolumn{2}{l|}{$\begin{array}{l}\text { Do you have the } \\
\text { disease? }\end{array}$} & \multicolumn{2}{l|}{$\begin{array}{l}\text { Are you being treated } \\
\text { for the disease? }\end{array}$} & \multicolumn{2}{l|}{$\begin{array}{l}\text { Does the disease } \\
\text { limit you? }\end{array}$} \\
\hline DISEASE & YES & NO & YES & NO & YES & NO \\
\hline Heart disease & & & & & & \\
\hline High blood pressure & & & & & & \\
\hline Lung disease & & & & & & \\
\hline Diabetes & & & & & & \\
\hline $\begin{array}{l}\text { Stomach ulcer or other } \\
\text { stomach disease }\end{array}$ & & & & & & \\
\hline Kidney disease & & & & & & \\
\hline Liver disease & & & & & & \\
\hline $\begin{array}{l}\text { Anemia or other blood } \\
\text { disease }\end{array}$ & & & & & & \\
\hline Cancer & & & & & & \\
\hline Depression & & & & & & \\
\hline Arthritis & & & & & & \\
\hline Back pain & & & & & & \\
\hline Rheumatoid disease & & & & & & \\
\hline Other physical disability & & & & & & \\
\hline $\begin{array}{l}\text { Some other disease, } \\
\text { what? }\end{array}$ & & & & & & \\
\hline
\end{tabular}

(13) a) Do you have diabetes? No [0]. Yes, treated with tablets [1]. Yes, insulin diabetes [2].
b) Do you have$$
\text { thyroid dysfunction? } \quad \text { No [0] Yes [1] }
$$

$$
\begin{aligned}
& \text { If you answered yes, do you have } \\
& \text { hypothyrosis [2] hyperthyrosis [3] }
\end{aligned}
$$

c) Do you have Dupuytren's contracture?

No [0] Yes, in my hand [1] Yes, in my foot [2] Yes, elsewhere [3]

d) Do you have epilepsy? No [0] Yes [1]

e) Have you had a stroke in your brain? $\quad$ No [0] Yes [1]

f) Has your close relative had a frozen shoulder? No [0] Yes [1]

(14) Has your other shoulder been frozen too? No [0] Yes [1]

(15) Do you use regular medication? $\quad$ No [0] $\quad$ Yes [1]

If yes, which medication do you use?

(16) Generally, do you consider your health:

$\begin{array}{lc}\text { Very good } & {[1]} \\ \text { Good } & {[2]} \\ \text { Partly good/partly bad } & {[3]} \\ \text { Bad } & {[4]} \\ \text { Very bad } & {[5]}\end{array}$

If you answered 3-5, then why? $\mathrm{cm}$.

(17) My height is

(18) My weight is $\mathrm{kg}$. 


\section{Present state of the once frozen shoulder}

(19) Has your once frozen shoulder disturbed your activities of daily living (cooking, cleaning, shopping, etc) during the last year?

$$
\text { Yes [1] No [0] }
$$

(20) Has your once frozen shoulder disturbed your enjoyment of your hobbies during the last year?

$$
\text { Yes [1] No [0] }
$$

(21) How much pain do you have today in your shoulder, on a scale of 0 to 10 ?

$0=$ no pain, $10=$ the worst pain imaginable

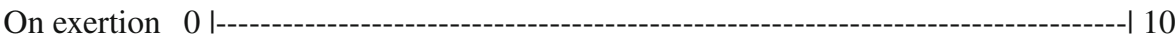

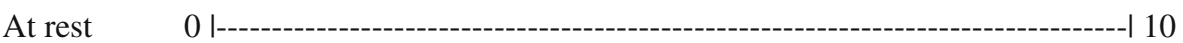

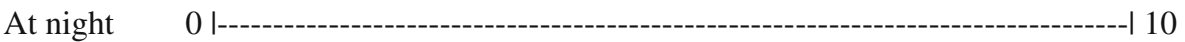

(22) Have you had pain in the once frozen shoulder during the last year?

$$
\text { Yes [1] No [0] }
$$

If you answered No to question 22, you can continue to question $\mathbf{2 5}$

(23) Have you needed pain medication for the pain in the once frozen shoulder during the last year?

$$
\text { Yes [1] No [0] }
$$

If you answered No to question 23 , you can continue to question $\mathbf{2 5}$

(24) How often have you used pain medication for pain in the once frozen shoulder the last year?

$\begin{array}{lc}\text { Once a month or less often } & {[1]} \\ \text { More often, but less than once a week } & {[2]} \\ \text { Weekly, but not every day } & {[3]} \\ \text { Daily } & {[4]}\end{array}$

(25) Have you had a bone fracture around the once frozen shoulder? Yes [1] No [0]

If you answered No to question $\mathbf{2 5}$, you can continue to question 27.

(26) If you answered Yes to question 25, then what fracture did you have, when and at what hospital was it treated?

(27) Have you needed an operation on the once frozen shoulder?

$$
\text { Yes [1] No [0] }
$$

If you answered Yes, then where and when was the operation done?

(28) Would you again choose the same treatment for a frozen shoulder under the same circumstances?

$$
\text { Yes [1] No [0] }
$$

(29) Regarding the end result, are you: Very satisfied [1]

Satisfied [2]

Partly satisfied/partly unsatisfied [3]

Unsatisfied [4]

If you answered 3-5, then why?

Very unsatisfied [5]

(30) Free comments 


\section{References}

1. Binder AI, Bulgen DY, Hazleman BL, Roberts S. Frozen shoulder: a long-term prospective study. Ann Rheum Dis. 1984; 43:361-364.

2. Bulgen DY, Binder AI, Hazleman BL, Dutton J, Roberts S. Frozen shoulder: prospective clinical study with an evaluation of three treatment regimens. Ann Rheum Dis. 1984;43:353-360.

3. Codman RA. The Shoulder. Boston, MA: Thomas Todd Co; 1934:216-224.

4. Constant CR, Murley AH. A clinical method of functional assessment of the shoulder. Clin Orthop Relat Res. 1987;214: 160-164.

5. Diercks RL, Stevens M. Gentle thawing of the frozen shoulder: a prospective study of supervised neglect versus intensive physical therapy in seventy-seven patients with frozen shoulder syndrome followed up for two years. J Shoulder Elbow Surg. 2004;13:499_ 502.

6. Dudkiewicz I, Oran A, Salal M, Palti R, Pritsch M. Idiopathic adhesive capsulitis: long-term results of conservative treatment. Israel Med Assoc J. 2004;6:524-526.

7. Griggs SM, Ahn A, Green A. Idiopathic adhesive capsulitis: a prospective functional outcome study of nonoperative treatment. J Bone Joint Surg Am. 2000;82:1398-1407.

8. Hand C, Clipsham K, Rees JL, Carr AJ. Long-term outcome of frozen shoulder. J Shoulder Elbow Surg. 2008;17:231-236.

9. Hirschmann MT, Wind B, Amsler F, Gross T. Reliability of shoulder abduction strength measure for the Constant-Murley score. Clin Orthop Relat Res. 2010;468:1565-1571.
10. Hsu JE, Anakwenze OA, Warrender WJ, Abboud JA. Current review of adhesive capsulitis. J Shoulder Elbow Surg. 2011; 20:502-514.

11. Katolik LI, Romeo AA, Cole BJ, Verma NN, Hayden JK, Bach BR. Normalization of the Constant score. J Shoulder Elbow Surg. 2005;14:279-285.

12. Levine WN, Kashyap CP, Bak SF, Ahmad CS, Blaine TA, Bigliani LU. Nonoperative management of idiopathic adhesive capsulitis. J Shoulder Elbow Surg. 2007;16:569-573.

13. Melzer C, Wallny T, Wirth CJ, Hoffmann S. Frozen shoulder: treatment and results. Arch Orthop Trauma Surg. 1995;114:87-91.

14. Meulengracht E, Schwartz M. The course and prognosis of periarthritis humeroscapularis with special regard to cases with general symptoms. Acta Med Scand. 1952;118:350-360.

15. Miller M, Wirth M, Rockwood C Jr. Thawing the frozen shoulder: the "patient" patient. Orthopedics. 1996;19:849-853.

16. Othman A, Taylor G. Is the Constant scale reliable in assessing patients with frozen shoulder? 60 shoulders scored 3 years after manipulation under anaesthesia. Acta Orthop Scand. 2004;75: 114-116.

17. Reeves B. The natural history of the frozen shoulder syndrome. Scand J Rheum. 1975;4:193-196.

18. Shaffer B, Tibone J, Kerlan R. Frozen shoulder: a long-term follow-up. J Bone Joint Surg Am. 1992;74:738-746.

19. Simmonds FA. Shoulder pain: with particular reference to the "frozen" shoulder. J Bone Joint Surg Br. 1949;31:426-432.

20. Simple Shoulder Test. Available at: www.orthop.washington. edu/.../OurServices/ShoulderElbow/Articles/SimpleShoulderTest. aspx. Accessed October 18, 2011. 